MEXАНIKA

MECHANICS

https://doi.org/10.15407/dopovidi2021.05.039

удК 628.35
О.Я. Олійник
С.В. Телима, https://orcid.org/0000-0003-0109-0696
Ю.І. Калугін, https://orcid.org/0000-0003-0720-0665
Е.О. Олійник

Інститут гідромеханіки НАН України, Київ

E-mail: sertelyma@gmail.com

\title{
Моделювання і розрахунки очистки стічних вод від сполук азоту в біореакторах з використанням біоплівкових моделей
}

Представлено иленом-кореспондентом НАН Украйни О.Я. Олійником

Запропоновано математичну модель та розрахунки параметрів очистки стічних вод від сполук амонійного азоту (нітрифікація) в біореакторах з додатковим облаштуванням в їх об'ємі закріпленого біоценозу у вигляді біоплівки. Дана оцінка впливу різних факторів на параметри очистки. В моделі використовується кінетика реакцій згідно нелінійного рівняння Моно, що дозволяє проводити розрахунки по визначенню конщентрацій азоту на зовнішній та внутрішній поверхнях біоплівки та оцінювати ефективність дії біоплівки заданої товщини по характеру проникнення в ній забруднень азоту. При цьому потік субстрату та глибина проникнення в біоплівку є функціями конщентрації субстрату на поверхні біоплівки, швидкості реакиії всередині біоплівки і дифузійного масопереносу. У якості основного параметра для оцінки впливу кисню, який контролює процес окислення амонію до нітритів, пропонується використання відношення конщентрацій кисню до амонійного азоту. Як показали конкретні приклади і розрахунки, дане відношення може бути кращою альтернативою контролю за нітрифікацією в реакторі у порівнянні з концентрацією кисню.

Ключові слова: модель, очистка, сполуки азоту, біоплівка, біореактор, кисень, концентрації.

Відомо [1-4], що одним із основних забруднень, яке входить до складу господарськопобутових стічних вод, і подібних їм за складом є сполуки азоту переважно амонійної форми $\left(\mathrm{NH}_{4}^{+}-\mathrm{N}\right)$. Згідно з існуючими нормативними вимогами, ці води перед скиданням у різні водойми підлягають значному очищенню. В практиці очищення стічних вод від сполук азоту, як і забруднень органічного походження, найбільше застосовуються біологічні методи очистки, їх основна складова - біореактор-аеротенк. В аеротенку відбувається

Ц и т у в а н н я: Олійник О.Я., Телима С.В., Калугін Ю.І., Олійник Е.О. Моделювання і розрахунки очистки стічних вод від сполук азоту в біореакторах з використанням біоплівкових моделей. Допов. Нац. акад. наук Укр. 2021. № 5. С. 39-49. https://doi.org/10.15407/dopovidi2021.05.039 
вилучення (біоокиснення) сорбованих на плаваючих пластівцях активного мулу, який в даному випадку складається із автотрофних мікроорганізмів, завислих або розчинених у воді азотних забруднень. Проте натепер, особливо в зв'язку з підвищенням нормативних вимог, така очистка не забезпечує необхідного ступеня і якості вилучення азотних забруднень зваженим (плаваючим) біоценозом, а це потребує додаткової очистки. Виконаний аналіз показав, що ефективність вилучення забруднень азоту в аеротенках можна значно підвищити, якщо поряд зі зваженим біоценозом (активним мулом) забезпечити в об'ємі аеротенка додаткове завантаження (різні сорбенти, пристрої, насадки тощо), на поверхні якого утворюється біоплівка з високою концентрацією мікроорганізмів. Така комбінована біологічна очистка стічних вод в спорудах з закріпленим біоценозом (біоплівкою) на думку спеціалістів має ряд значних технологічних переваг і може широко використовуватись на практиці при вилученні забруднень різного походження. Нагадаємо, що в загальному випадку вилучення $\mathrm{N}-\mathrm{NH}_{4}^{+}$в цілому складається із декількох процесів, а саме -3 процесу окиснення амонію до нітритів $\mathrm{N}-\mathrm{NO}_{2}^{+}$(перша стадія нітрифікації), окиснення нітратів $\mathrm{N}-\mathrm{NO}_{2}$ до нітратів $\mathrm{N}-\mathrm{NO}_{3}$ (друга стадія нітрифікації) і із майже анаеробного процесу денітрифікації - відновлення зазначених сполук азоту до молекулярного $\mathrm{N}_{2}$.

В наведеній роботі побудовано математичну модель, в якій розглядається перша стадія нітрифікації з вилучення $\mathrm{N}-\mathrm{NH}_{4}^{+}$. Таке вилучення відбувається аеробними бактеріями Nitrosomonas за необхідності забезпечення процесу очистки киснем.

Для одержання інженерних оцінок і аналізу розглянемо біореактор-аеротенк-змішувач, в якому вилучення $\mathrm{NH}_{4}^{+}$відбувається зваженим (активним мулом) і закріпленим біоценозом у вигляді біоплівки з високою концентрацією мікроорганізмів, яка утворюється на поверхні додатково облаштованого в аеротенку завантаження. При формуванні моделі вилучення азоту біоплівкою необхідно враховувати той факт, що концентрація азоту, який поступає в біоплівку із рідини аеротенка на утилізацію проходить у вигляді потоку через пограничний шар. В зв’язку з тим, що в промежовому шарі відбуваються різні перетворення за рахунок процесів масообміну і масопереносу концентрація азоту на зовнішній поверхні біоплівки буде відрізнятись від концентрації азоту в аеротенку. В результаті проведеного аналізу встановлено, що в даному випадку потік азоту в промежовому шарі буде дорівнювати потоку азоту на поверхні, що і було прийнято при реалізації біоплівкових моделей. Таким чином, в умовах достатнього забезпечення аеробного процесу вилучення азоту киснем загальна балансова математична модель вилучення азоту, яка записана відносно зміни концентрації амонійного азоту в стічній воді, що очищається в біореакторі (аеротенку-змішувачі), біоплівці і рідинній плівці промежового шару, буде мати вигляд

$$
W_{p} \frac{d \mathrm{~N}_{a}}{d t}=Q_{a}\left(\mathrm{~N}_{0}-\mathrm{N}_{a}\right)-F_{\delta_{e}} I_{N}-R_{a_{0}} W_{p} .
$$

У практичних розрахунках достатньо розглянути рівняння (1) в стаціонарних умовах і привести його до такого вигляду:

$$
\mathrm{N}_{0}-\mathrm{N}_{a}-F_{\delta_{n}} T_{a} I_{\mathrm{N}}-R_{a} T_{a}=0
$$


де $\quad F_{\delta_{n}}=\frac{F_{\delta_{e}}}{W_{p}} ; \quad T_{a}=\frac{W_{p}}{Q_{a}} ; \quad I_{\mathrm{N}}=K_{n}\left(\mathrm{~N}_{a}-\mathrm{N}_{\delta_{0}}\right), \quad W_{p}=W_{a} \varepsilon ; \quad \mathrm{N}_{\delta_{0}}=\left.\mathrm{N}\right|_{z=0} ; \quad R_{a_{0}}=R_{a}-R_{c} ; \quad \varepsilon=$ $=1-\frac{W_{\delta}}{W_{a}}=\frac{W_{p}}{W_{a}} ; R_{a}, \quad R_{c}-$ швидкість реакцій утилізації азоту зваженим біоценозом (активним мулом) і виділених речовин при відмиранні мулу; $I_{\mathrm{N}}-$ потік (транспорт) сполук азоту через поверхню біоплівки для їх утилізації закріпленим біоценозом (біоплівкою); $\mathrm{N}, \mathrm{N}_{\delta_{0}}, \mathrm{~N}_{0}, \mathrm{~N}_{a}-$ відповідно концентрації азоту в біоплівці на поверхні біоплівки, на вході і в аеротенку; $W_{a}, W_{p}, W_{\delta}-$ відповідно робочий об'єм аеротенка, об'єм рідини в аеротенку, об'єм встановленого завантаження (насадки) із закріпленим біоценозом; $Q_{a}-$ витрата рідини в аеротенку; $F_{\delta_{e}}-$ загальна площа поверхні біоплівки; $K_{n}-$ коефіцієнт масопереносу забруднень азотом в рідинній плівці (через промежевий шар); $\delta, \delta_{n}-$ відповідно товщини біоплівки і рідинної плівки (промежевого шару).

Згідно з (2) при відомих (заданих концентраціях азоту в стічних водах, які надходять в біореактор $\mathrm{N}_{0}$ ) і очищених в стічній воді зваженим біоценозом (активним мулом) $\mathrm{N}_{a}$ тривалість аерації $T_{a}$ для забезпечення процесу окиснення буде складати

$$
T_{a}=\frac{\mathrm{N}_{0}-\mathrm{N}_{a}}{F_{\delta_{n}} I_{\mathrm{N}}}
$$

де $F_{\delta_{n}}-$ питома площа поверхні біоплівки в біореакторі.

Так як в даному випадку вилучення азоту переважно відбувається біоплівкою і визначається, зокрема, згідно з рівнянням потоку азоту $I_{\mathrm{N}}$ в біоплівку через її поверхню, то в подальшому його визначення відбувається на основі реалізації наступних біоплівкових моделей:

а) в загальному випадку в умовах елементів можливого завантаження, на якому формується біоплівка в біореакторі-аеротенку:

$$
\frac{\partial \mathrm{N}}{\partial t}=D_{\mathrm{N}} \frac{\partial^{2} \mathrm{~N}}{\partial z^{2}}-R_{\mathrm{N}}
$$

б) в умовах завантаження із елементів циліндричної форми (насадки, сітки тощо), на яких утворюється біоплівка:

$$
\frac{\partial \mathrm{N}}{\partial t}=D_{\mathrm{N}}\left(\frac{\partial^{2} \mathrm{~N}}{\partial r^{2}}+\frac{1}{r} \frac{\partial \mathrm{N}}{\partial r}\right)-R_{\mathrm{N}},
$$

де $R_{\mathrm{N}}$ - швидкість реакції в біоплівці при повній відсутності інгібованого впливу, яка описується відомим рівнянням Моно [2, 5]:

$$
R_{\mathrm{N}}=\frac{\rho_{m} \mathrm{~N}}{K_{m_{\mathrm{N}}}+\mathrm{N}}, \quad \rho_{m}=\frac{\mu_{m} X_{\mathrm{N}}}{Y_{\mathrm{N}}} .
$$

Розв’язання рівнянь (4) і (5) дозволяє визначити концентрацію азоту за товщиною біоплівки $\delta$ i, головне для подальших розрахунків, концентрацію азоту на зовнішній i 
внутрішній поверхнях біоплівки $\mathrm{N}_{\delta_{0}}$ i $\mathrm{N}_{\delta_{n}}$, а також значення потоку $I_{\mathrm{N}}$ в біоплівці, яке можна записати в наступній безрозмірної формі:

$$
\frac{d^{2} \mathrm{~N}}{d \bar{z}^{2}}-\alpha_{\mathrm{N}} \frac{\overline{\mathrm{N}}}{\bar{K}_{m_{\mathrm{N}}}+\overline{\mathrm{N}}}=0
$$

розв’язок якого виконується за граничних умов:

при $\bar{z}=0 \quad \frac{d \mathrm{~N}}{d \bar{z}}=\gamma_{\mathrm{N}}(1-\overline{\mathrm{N}}) \quad$ при $\quad \bar{z}=1 \quad \frac{d \mathrm{~N}}{d \bar{z}}=0$.

Тут $\bar{z}=\frac{z}{\delta}, \quad \overline{\mathrm{N}}=\frac{\mathrm{N}}{\mathrm{N}_{a}}, \quad \alpha_{\mathrm{N}}=\frac{\mu_{m} X_{N} \delta^{2}}{Y_{N} D_{N} \mathrm{~N}_{a}}, \quad \gamma_{\mathrm{N}}=\frac{K_{N} \delta}{D_{N}}, \quad \bar{K}_{m_{N}}=\frac{K_{m_{N}}}{\mathrm{~N}_{a}}$.

Зазначимо, що гранична умова при $\bar{z}=0$ прийнята за умови, що значення потоку у промежовому шарі дорівнює потоку на поверхні біоплівки. В цьому випадку загальна залежність для визначення потоку в біоплівку буде мати такий вигляд :

$$
I_{\mathrm{N}}=K_{\mathrm{N}} \mathrm{N}_{a}\left(1-A_{\mathrm{N}}\right), \quad A_{\mathrm{N}}=\frac{\mathrm{N}_{\delta_{0}}}{\mathrm{~N}_{a}} .
$$

Для зручності подальших розрахунків залежність (9) представимо у вигляді

$$
I_{\mathrm{N}}=\bar{I}_{\mathrm{N}} \lambda, \quad \lambda=\frac{D_{\mathrm{N}}}{\delta} \mathrm{N}_{a}
$$

В результаті аналітичного розв’язку рівняння (7) за граничних умов (8) для визначення відносного потоку $\bar{I}_{\mathrm{N}}$ одержимо наступне рівняння:

$$
\bar{I}_{\mathrm{N}}=\sqrt{2 \alpha_{N}} \sqrt{\overline{\mathrm{N}}_{\delta_{0}}-\overline{\mathrm{N}}_{\delta_{1}}-\bar{K}_{m_{N}} \ln \left(\frac{\overline{\mathrm{N}}_{\delta_{0}}+\bar{K}_{m_{\mathrm{N}}}}{\overline{\mathrm{N}}_{\delta}+\bar{K}_{m_{\mathrm{N}}}}\right)}
$$

а також рівняння, яке зв’язує концентрації $\mathrm{N}_{\delta_{0}}$ i $\mathrm{N}_{\delta_{1}}$ на зовнішній і внутрішній поверхнях біоплівки:

$$
\overline{\mathrm{N}}_{\delta_{0}}=\overline{\mathrm{N}}_{\delta_{1}}+\bar{K}_{m_{N}} \ln \left(\frac{\overline{\mathrm{N}}_{\delta_{0}}+\bar{K}_{m_{N}}}{\overline{\mathrm{N}}_{\delta_{1}}+\bar{K}_{m_{N}}}\right)+\eta\left(1-\overline{\mathrm{N}}_{\delta_{0}}\right)^{2}
$$

де $\eta_{\mathrm{N}}=\frac{\gamma_{\mathrm{N}}^{2}}{2 \alpha_{N}}=\frac{K_{\mathrm{N}}^{2} \mathrm{~N}_{a}}{2 D_{\mathrm{N}} \omega_{\mathrm{N}}}, \quad \omega_{\mathrm{N}}=\frac{\mu_{m} X_{\mathrm{N}}}{Y_{\mathrm{N}}}$.

При $\mathrm{N}_{\delta_{0}}>\mathrm{N}_{\delta_{1}}$ можна знехтувати концентрацією $\mathrm{N}_{\delta_{1}}$ в залежностях (11) i (12). Це дозволяє в практичних розрахунках визначати потік $I_{\mathrm{N}}$ і концентрацію азоту, при яких відбувається перехід від частково проникної до повністю проникної біоплівки при заданих вихідних параметрах реакцій і товщині біоплівки. 
Так як на практиці концентрація азоту буде переважно значно більшою, ніж параметр напівнасичення $\mathrm{N}>>K_{m_{N}}$, то при вилученні азоту біоплівкою в біореакторах можна приймати кінетику реакції нульового порядку:

$$
R_{\mathrm{N}_{0}}=w_{\mathrm{N}}, \quad w_{\mathrm{N}}=\frac{\mu_{m} X_{\mathrm{N}}}{Y_{\mathrm{N}}} .
$$

Тоді при розв’язку рівняння

$$
D_{\mathrm{N}} \frac{d^{2} \mathrm{~N}}{d z^{2}}-w_{\mathrm{N}}=0
$$

в залежності від проникнення азоту в біоплівці необхідно розглядати два наступних випадки. В першому випадку, який відповідає повному проникненню азоту в біоплівку $\left(L_{\delta_{1}} \geqslant 0\right)$, розв’язок рівняння (14) виконується за наступних граничних умов:

$$
\begin{aligned}
& I_{\mathrm{N}}=-D_{\mathrm{N}} \frac{d \mathrm{~N}}{d z}=K_{\mathrm{N}}\left(\mathrm{N}_{a}-\mathrm{N}_{z=0}\right) \quad \text { при } \quad z=0, \\
& \frac{d \mathrm{~N}}{d z}=0 \quad \text { при } \quad z=\delta .
\end{aligned}
$$

В цьому випадку для визначення значень концентрацій $\mathrm{N}, \mathrm{N}_{\delta_{0}}, \mathrm{~N}_{\delta_{1}}$ одержимо

$$
\begin{aligned}
& \mathrm{N}=\mathrm{N}_{a}-\frac{w_{\mathrm{N}}}{D_{\mathrm{N}}}\left(\frac{\delta D_{\mathrm{N}}}{K_{\mathrm{N}}}+\delta z-\frac{z^{2}}{2}\right), \\
& \mathrm{N}_{\delta_{0}}=\mathrm{N}_{a}-\frac{\omega_{\mathrm{N}} \delta}{K_{\mathrm{N}}}, \\
& \mathrm{N}_{\delta_{1}}=\mathrm{N}_{\delta_{0}}-\frac{\omega_{\mathrm{N}}}{2 D_{N}} \delta^{2} .
\end{aligned}
$$

Для подальшого аналізу рівняння (18) запишемо у вигляді

$$
\mathrm{N}=\mathrm{N}_{\delta_{0}}\left[1-\left(\frac{2 z}{\delta \beta_{N}^{2}}-\frac{z^{2}}{\delta^{2} \beta_{N}^{2}}\right)\right]
$$

де $\beta_{\mathrm{N}}=\sqrt{\frac{2 \mathrm{~N}_{\delta_{0}} D_{\mathrm{N}}}{\omega_{\mathrm{N}} \delta^{2}}}$ або $\beta_{\mathrm{N}} \delta=\sqrt{\frac{2 \mathrm{~N}_{\delta_{0}} D_{\mathrm{N}}}{\omega_{\mathrm{N}}}}$. Параметр $\beta_{\mathrm{N}}$ характеризує зміну концентрації азоту в біоплівці і в даному випадку згідно (19) з $\beta_{\mathrm{N}}>1 \quad \mathrm{~N}_{\delta_{1}}>0$, а при $\beta_{\mathrm{N}}=1 \quad \mathrm{~N}_{\delta_{1}}=0$.

У випадку, коли спостерігається часткове проникнення азоту в біоплівку $\left(\beta_{\mathrm{N}}<1\right)$, тобто його вилучення відбувається на ділянці $z=\beta_{\mathrm{N}} \delta$, при розв’язку рівняння (14) приймаються граничні умови $\frac{d \mathrm{~N}}{d z}=0$ і $\mathrm{N}=0$. При граничній умові $\frac{d \mathrm{~N}}{d z}=0$ при $z=\beta_{\mathrm{N}} \delta$ для визначення значення концентрації на ділянці $0<z<\beta_{\mathrm{N}} \delta$ одержимо рівняння: 


$$
\begin{aligned}
& \mathrm{N}_{z}=\mathrm{N}_{\delta_{0}}-\left(z \beta_{\mathrm{N}} \delta-\frac{z^{2}}{2}\right) \frac{w_{\mathrm{N}}}{D_{\mathrm{N}}}, \\
& N_{\delta_{0}}=N_{a}-\frac{w_{N} \beta_{N} \delta}{K_{N}} .
\end{aligned}
$$

У випадку граничної умови $\mathrm{N}=0$ при $z=\beta_{\mathrm{N}} \delta=0$ при розв’язку рівняння (14) одержимо

$$
\begin{aligned}
& \mathrm{N}_{Z}=\mathrm{N}_{\delta_{o}}\left(1-\frac{2 z}{\beta_{N} \delta}+\frac{z^{2}}{\left(\beta_{N} \delta\right)^{2}}\right) \\
& \mathrm{N}_{\delta_{o}}=\frac{\mathrm{N}_{a}-w_{\mathrm{N}} \cdot \beta_{N} \delta}{\left(1-\frac{D_{N}}{\beta_{N} \delta K_{\mathrm{N}}}\right)}
\end{aligned}
$$

Якщо відношення $\frac{D_{\mathrm{N}}}{\beta_{N} \delta K_{N}}<<1$, то в обох випадках визначення концентрації $\mathrm{N}_{\delta_{o}}$ можна знаходити за формулою (21).

За рівнянням (20) потік в біоплівку при $\beta_{N}>1$ буде складати

$$
I_{N}=w_{N} \delta
$$

а в другому випадку - при $\beta_{\mathrm{N}}<1$ маємо

$$
I_{\mathrm{N}}=\omega_{\mathrm{N}} \beta_{\mathrm{N}} \delta
$$

Оскільки значення $\beta_{N}$ залежить від концентрацій, то вираз (24) можна записати у вигляді

$$
I_{\mathrm{N}}=\sqrt{2 D_{\mathrm{N}} \omega_{\mathrm{N}}} \cdot \sqrt{\mathrm{N}_{\delta_{o}}} .
$$

Таким чином, відношення потоків для реакцій нульового порядку для частково проникної біоплівки і для повністю проникної біоплівки будуть визначатись через параметр $\beta_{N}$.

Як уже зазначалось вище, ефективність вилучення азоту біоплівкою з використанням запропонованих методів розрахунку значною мірою буде залежати від прийнятої товщини біоплівки $\delta$. У такому випадку в умовах вилучення одного субстрату азоту автотрофними мікроорганізмами (процес нітрифікації) формується однорідна гомогенна структура активної біоплівки товщиною $\delta$. Проте слід відзначити, що на формування біоплівки впливають різні процеси, які згідно з $[5,6]$ в даному випадку можна враховувати на основі реалізації наступного загального рівняння:

$$
\frac{d \delta}{d t}=\int_{0}^{\delta} \frac{\mu_{m} \mathrm{~N}}{K_{m_{N}}+\mathrm{N}} d z-b_{s} \delta-u_{d s}
$$


В прийнятих моделях біоплівки для визначення її товщини $\delta$ рівняння (27) переважно розв'язується в стаціонарних умовах при $\frac{d \delta}{d t}=0$. В окремих випадках [5-7] пропонується використовувати більш спрощене балансове рівняння

$$
\frac{Y_{\mathrm{N}}}{X_{\mathrm{N}}} I_{\mathrm{N}}-b_{s} \delta-u_{d s}=0 .
$$

В прийнятих рівняннях $b_{s}-$ коефіцієнт, який враховує процеси розпаду біоплівки; $u_{d s}-$ швидкість відриву біомаси з поверхні біоплівки, для визначення якої рекомендуються залежності [5, 6]:

$$
\begin{aligned}
& u_{d s}=b_{d} \delta, \\
& u_{d s}=K_{d} \delta^{2} .
\end{aligned}
$$

Наприклад, якщо прийняти для реакції нульового порядку значення потоку за формулою (27), то на підставі розв'язку рівняння (28) з врахуванням формули (30) одержимо

$$
\delta=\frac{\mu_{m}-b}{K_{d}} .
$$

Нагадаємо, що у формулі (30) прийнято $\mu_{m}$, доба ${ }^{-1}, b$, доба ${ }^{-1}, K_{a} 1 /($ доба,,$\mu), \delta, \mu$.

В якості прикладу на основі розв'язку чисельними методами рівняння (27) в таблиці наведені значення товщини біоплівки $\delta$ в залежності від зміни концентрації $\mathrm{N}_{a}$, параметра $b$, а також при прийнятих значеннях вихідних параметрів, рекомендованих у роботах [5-7]:

$$
\mu_{m}=0,95 \text { доба }^{-1}, Y_{\mathrm{N}}=0,22 \text { гХПК } / 2 \mathrm{~N}, K_{m \mathrm{~N}}=1 \mathrm{rN} / \mathrm{m}^{3}, X_{\mathrm{N}}=10000 \text { гХПК } / \mathrm{m}^{3}, K_{\mathrm{N}}=0,10 \mathrm{м} / \text { год, }
$$
$\delta_{\min }=10$ мкм, $D_{\mathrm{N}}=1,70 \cdot 10^{-4} \mathrm{~m}^{2} /$ доба.

Згідно з рівнянням (27) і даними таблиці маємо: зі збільшенням параметра $b\left(K_{d}\right)$ потік азоту і товщина біоплівки зменшуються, тоді як зі збільшенням концентрації азоту в біореакторі $N_{a}$ ці характеристики збільшуються.

Як уже зазначалось вище, вилучення азоту біоплівкою відбувається за аеробних умов при забезпеченні киснем в достатній кількості, яка необхідна для росту і життедіяльності автотрофних мікроорганізмів. На підставі проведеного аналізу в практичних розрахунках параметрів кисневого режиму розглянемо випадок, коли вилучення азоту в біоплівці від-

Значення активної товщини біоплівки $\delta$, мкм в стаціонарних умовах при різних значеннях $b$, год $^{-1}$ i концентрацій $\mathrm{N}_{a}, \Gamma / \mathrm{m}^{3}$

\begin{tabular}{|c|c|c|c|c|c|c|}
\hline \multirow{2}{*}{$b$, год $^{-1}$} & \multicolumn{7}{|c|}{$\mathrm{N}_{a}$, г/ $\mathrm{M}^{3}$} \\
\cline { 2 - 7 } & 1 & 3 & 5 & 7 & 9 & 11 \\
\hline \multirow{2}{*}{0,01} & 100 & 260 & 410 & 570 & 680 & 750 \\
0,02 & - & 130 & 210 & 290 & 350 & 390 \\
0,03 & - & - & 90 & 160 & 200 & 250 \\
\hline
\end{tabular}


бувається за реакцією нульового порядку при окисненні (споживанні кисню), яке відбувається також за реакцією нульового порядку:

$$
R_{C}=\alpha_{1} R_{1}+\alpha_{2} b_{c} X_{\mathrm{N}}
$$

В результаті розв’язку наступного рівняння:

$$
D_{C} \frac{d^{2} C}{d z^{2}}-R_{C}=0
$$

за граничних умов

$$
\begin{aligned}
& -D_{C} \frac{d C}{d z}=K_{C}\left(C_{a}-C_{\delta_{0}}\right)=I_{C} \quad \text { при } z=0, \\
& \frac{d C}{d z}=0 \quad \text { при } z=\delta
\end{aligned}
$$

одержимо вирази для визначення концентрації $C_{\delta_{o}}$ і потоку $I_{C}$

$$
\begin{aligned}
& C_{\delta_{o}}=C_{a}-\frac{w_{c} \delta}{K_{C}}, \\
& I_{C}=w_{c} \delta,
\end{aligned}
$$

де

$$
w_{c}=\alpha_{1} R_{\mathrm{N}}+\alpha_{2} b_{c} X_{\mathrm{N}}
$$

При цьому витрата кисню на утилізацію (самоокиснення) відмираючого біоценозу в біоплівці врахована параметром $\alpha_{2} b_{c} X_{N}$.

В загальному випадку значення потоку кисню, який поступає в біоплівку, визначається за рівняннями (35) та (36). Проте, для реакції нульового порядку при неврахуванні процесів, які визначаються параметром $b_{c}$, тобто у випадку $b_{c}=0$, для визначення потоку $I_{C} 3$ врахуванням необхідних стехіометричних коефіцієнтів після деяких перетворень одержимо наступні залежності:

$$
I_{C}=\left(4,57-Y_{\mathrm{N}}\right) I_{\mathrm{N}}, \quad I_{N}=\frac{I_{C}}{\left(4,57-Y_{\mathrm{N}}\right)}, \quad Y_{\mathrm{N}} \approx 0,22,
$$

тобто значення $\alpha_{1}$ буде дорівнювати $\alpha_{1}=\alpha_{N}-Y_{N}, \quad \alpha_{N}=4,57 \Gamma_{2} \mathrm{O}_{2} /$ гN

Процеси вилучення азоту біоплівкою в аеробних умовах контролюються проникненням кисню. Тому визначення і порівняння параметрів проникнення (пенетрації) в біоплівку забруднень і кисню являється найбільш важливим результатом кінематичних досліджень в біоплівках, так як дозволяє визначити, який із них буде лімітувати процес утилізації субстрату (азоту). В загальному випадку це питання може бути вирішено за рахунок порівняння і аналізу побудованих в біоплівці епюр зміни концентрацій $\mathrm{N}$ і С за товщиною біоплівки. 
При цьому азот може бути присутній по всій товщині біоплівки, але не може бути вилучений на ділянках, куди не може проникнути кисень в достатній кількості.

В літературі для різних кінетик реакцій з використанням стехіометричних коефіцієнтів обгрунтовано і запропоновано ряд критеріїв. Так, в роботах $[1,5]$ в умовах кінетики нульового порядку за рахунок зіставлення значень концентрацій $\mathrm{N}_{\delta_{o}}$ i $\mathrm{C}_{\delta_{o}}$ i потоків $\mathrm{I}_{\mathrm{C}}$ i $\mathrm{I}_{\mathrm{N}}$ , а також відомих параметрів проникнення $\beta_{\mathrm{C}}$ i $\beta_{\mathrm{N}}$ можна визначити, який із субстратів лімітує конверсійні процеси всередині біоплівки. Наприклад, результати розрахунків показали, що в більшості випадків, а саме, в умовах $\mathrm{N}_{\delta}>0,3 C_{\delta_{0}}$ та $\beta_{C}<\beta_{N}$ вилучення амонію обмежується киснем, особливо за товщиною біоплівки, що необхідно враховувати в інженерних розрахунках очистки біоплівкою.

На процеси і механізми вилучення амонійного азоту із стічних вод закріпленим біоценозом впливає температура, РН (лужність) і наявність інших речовин [8]. Вплив зазначених факторів в запропонованих моделях можна врахувати поправочними коефіцієнтами $f_{T}, f_{p H}, f_{i}$. На кінетику біоокиснення, а також процеси масопереносу впливає температура, проте цей вплив в умовах закріпленого біоценозу буде меншим, ніж за умов зваженого біоценозу (активного мулу). При цьому відомо, що для практичних розрахунків врахування впливу температури здійснюється шляхом корегування окремих кінетик і коефіцієнтів на відомий температурний фактор [1, 6]. Зокрема показано, що за умов лімітації процесу вилучення азоту киснем зміна температури в межах 14 до $27^{\circ} \mathrm{C}$ майже не впливає на процес нітрифікації [1, 8].

Вплив рН (лужність) особливо проявляється в процесах нітрифікації в основному при вилученні амонію N. Аналіз оцінки впливу різних параметрів, приклади розрахунку лужності $\mathrm{HCO}_{3}$, необхідних для підтримки заданих $\mathrm{pH}$ і інших факторів при окисненні амонію $N$, розглянуті, зокрема, в роботах [3, 8]. При цьому значення $\mathrm{pH}<6,0$ практично може звести до інгібування процесу. Конкретні рекомендації щодо $\mathrm{pH}$, а також параметри $f_{p h}$ i ступінь їх впливу на процеси вилучення азоту наведені в роботах $[2,3,8]$. Так, зокрема, для визначення поправочного коефіцієнту $f_{p h}$ пропонуються наступні залежності:

$$
\begin{aligned}
& f_{p h} \approx 0 \text { при } p h<6,0, \\
& f_{p h}=1-0,833(7,2-p h) \text { при } 6<p h<7,2, \\
& f_{p h}=1 \text { при } p h \geqslant 7,2 .
\end{aligned}
$$

Відомо [1, 6], що за наявності в стічній воді токсичних і інших речовин швидкість реакції може істотно зменшуватись за рахунок інгібуючого (тормозного) їх впливу. При цьому в загальному випадку вплив різних речовин можна врахувати шляхом використання для опису процесу біоокиснення замість рівняння Моно (6) відоме рівняння Халдейна, а також інші рівняння кінетичних реакцій. В роботі $[1,9]$ наведені конкретні дані, які дозволяють оцінити інгібуючий вплив різних металів та інших речовин на процеси нітрифікації.

В подальшому передбачається проведення теоретичних досліджень очистки азоту в умовах другої стадії нітрифікації. Зокрема, спочатку буде проведено теоретичне обгрунтування процесів і побудова математичних моделей, які описують перетворення амонію при окисненні в нітрити $N \rightarrow N O_{2}^{+}$, які потім під дією інших бактерій окиснюють їх до ні- 
тратів $N-\mathrm{NO}_{3}^{+}$. Слід відзначити, що за умов досить складного анаеробного процесу денітрифікації під дією особливого роду бактерій нітрат перетворюється у вільний азот.

\section{ЦИТОВАНА ЛІТЕРАТУРА}

1. Henze M., Harremoes P., Jansen C., Arwin E. Wastewater Treatment. Berlin, New York: Springer, 2002. 430p.

2. Яковлев С.В., Воронов Ю.В. Водоотведение и очистка сточных вод. Москва: АСВ, 2002. 704 с.

3. Gujer W. Nitrification and me - A subjective review. Water. Res. 2010. № 44. P. 1-19.

4. Олейник А.Я., Тетеря А.И. Особенности моделирования процессов удаления азота из сточных вод на малогабаритных установках биологической очистки. Прикл. гидромеханика. 2001. 3 (75), № 3. C. $59-65$.

5. Henze M., M. Van Loosdrecht M.E., Ekama G.A., Brdjanovic D. Biological Wastewater Treatment. London: IWA Publishing, 2008. 511 p.

6. Wanner O., Ebert N.I., Rittman B.E. Mathematical Modeling of biofilms. Scientifical Technical report. 2006. № 18.208 p.

7. Perez M., Piccioreanu C., van Loosdrecht M. Modeling biofilm and flosdiffusion processes based on analytical solution of reaction - diffusion equations. Water Res. 2005. 39. P. 1311-1323.

8. Zhu S., Chen S. The impact of temperature on nitrification rate in fixed film biofilters. Aquacul. Eng. 2002. 26. P. 331-237.

9. Shabbir H.G., Rupa K.P., Ajit P.A. Nitrification modeling in biofilms under inhibitory conditions. Water. Res. 2004. № 38. P. 3179-3188.

Надійшло до редакції 30.05.2021

\section{REFERENCES}

1. Henze, M., Harremoes, P., Jansen, C. \& Arwin, E. (2007). Wastewater Treatment. Berlin, New York: Springer.

2. Yakovlev, S. V. \& Voronov, Yu. V. (2002). Drainage and wastewater treatment. Moscow: ACB (in Russian).

3. Gujer, W. (2010). Nitrification and me - A subjective review. Water. Res. No. 44. pp. 1-19.

4. Oleynik, A. Ya. \& Teterya, A. I. (2001). Peculiarities of modeling nitrogen removal processes from wastewater at small-scale biological treatment plants. Applied Hydromechanics. 3 (75), № 3, pp. 59-65 (in Russian).

5. Henze, M., M. Van Loosdrecht, M. E., Ekama, G. A. \& Brdjanovic, D. (2008). Biological Wastewater Treatment. London: IWA Publishing.

6. Wanner, O., Ebert, N. I. \& Rittman, B. E. (2006). Mathematical Modeling of biofilms. Scientifical Technical report, № 18.

7. Perez, M., Piccioreanu, C. \& van Loosdrecht, M. (2005). Modeling biofilm and flosdiffusion processes based on analytical solution of reaction - diffusion equations. Water Res., 39, pp. 1311-1323.

8. Zhu, S. \& Chen, S. (2002). The impact of temperature on nitrification rate in fixed film biofilters. Aquacul. Eng. 26. pp. 331-237.

9. Shabbir, H. G., Rupa, K. P. \& Ajit, P. A. (2004). Nitrification modeling in biofilms under inhibitory conditions. Water. Res. № 38, pp. 3179-3188.

Received 30.05.2021 
O.Ya. Oliynyk

S.V. Telyma, https://orcid.org/0000-0003-0109-0696

Yu.I. Kalugin, https://orcid.org/0000-0003-0720-0665

Ye.O. Oliynyk

Institute of Hydromechanics of the NAS of Ukraine, Kyiv

E-mail: sertelyma@gmail.com

\section{MODELING AND CALCULATIONS OF WASTE WATER TREATMENT FROM NITROGEN COMPOUNDS IN BIOREACTORS WITH THE USE OF BIOFILM MODELS}

The mathematic model and calculations of the waste waters cleaning parameters from the compounds ammonium nitrogen (nitrification) in bioreactors with the additional using of the fixed biocenosis as the biofilm in their volume are proposed. The valuation of the different influence factors on the waste waters cleaning parameters is given. The kinetics of reaction according to the Monod nonlinear equation is used that allowed us to calculate the nitrogen concentrations on the external and internal biofilm surfaces and to evaluate the efficiency of the biofilm work of the given thickness relative to the penetration character of the nitrogen pollutions in it. At this, the substrate flow and the penetration depth into the biofilm are functions of the substrate concentration on the biofilm surface, rate of the reaction within it, and the diffusive mass transfer. As a main parameter for the evaluation of the oxygen influence for the control over the process of ammonium oxidation to nitrite, the relation of the concentrations oxygen to ammonium nitrogen is proposed. The specific examples and calculations have showed that the given relation may be a better alternative for the control over the nitrification processes in the reactor in comparison with oxygen concentration.

Keywords: model, cleaning, nitrogen compounds, biofilm, bioreactor, oxygen, concentration. 